\title{
KONSEP MAQASHID SYARIAH PADA UMKM DALAM UPAYA MENDUKUNG AKSELERASI PANGSA EKONOMI SYARI'AH JAWA TIMUR
}

\author{
M. Zikwan \\ ziksaririzik@gmail.com \\ Fakultas Syari'ah dan Ekonomi Islam Universitas Ibrahimy
}

\begin{abstract}
ABSTRAK
The existence of UMKM is very urgent for the community because it can provide solutions for workers who have not been accommodated. This is because UMKM are businesses that come from someone's creative thinking and do not have high criteria in absorbing labor. The reality is that UMKM have been able to survive in the welfare of people's lives both under normal conditions or in conditions of economic crisis, in fact in the 1997 economic crisis UMKM were able to provide solutions and continue to survive until economic conditions returned to stable. Along with the rapid development of UMKM, it often causes local conflicts and so on, to prevent this it is necessary to take preventive actions taken by the government against UMKM based on sharia principles. To realize UMKM that are in accordance with sharia principles, it is necessary to involve the government to make regulations related to the technical and implementation of UMKM. The standards for sharia UMKM are UMKM that have implemented sharia principles. There are five aspects that must be guarded by humans, namely religion (حفظ ) soul (حفظ) (حفظ العقل) intellect (حفظ النسل) pffspring property (حفظ المسال).
\end{abstract}

Keyword: Maqashid as-Syari'ah, UMKM

\section{PENDAHULUAN}

Sebagai agama rahmatal lil 'alamin, Islam merupakan ajaran yang komprehensif dan universal. Dikatakan komprehensif karena ajaran Islam mencakup dua aspek besar, yaitu ajaran tentang hubungan manusia dengan Allah SWT (habl min Allah) dan hubungan manusia sesama manusia sebagai makhluk sosial (habl min an-Nas). Universal berarti ajara Islam dapat diterapkan disetiap waktu dan keadaan, artinya kapanpun dan dimanapun 
manusia berada maka ajaran Islam tetap melekat pada dirinya. Oleh karena itu, Islam sesungguhnya tidak hanya mengatur urusan ibdah semata, akan tetapi jauh daripada itu Islam mengatur sendi-sendi kehidupan manusia, baik urusan persoalan dunia lebih-lebih persoalan akhirat kelak.

Secara garis besar, esensi ajara Islam terbagi menjadi tiga: pertama, ajaran yang mengatur tentang hubungan manusia (sebagai makhluk) kepada Allah (sebagai khaliq), ajaran ini lebih dikenal dengan sebutan ibadah. Kedua, ajaran yang mengatur tentang tingkahlaku manusia, baik kepada tuhan, kepada sesama manusia maupun kepada sesama makhluk hidup lainnya, ajaran ini lebih dikenal dengan sebutan akhlak. Ketiga, ajaran yang mengatur hubungan manusia sebagi makhluk sosial (zoonpoliticon) baik dalam urusan, Negara, politik serta urusan pemenuhan kebutuhan manusia (persoalan ekonomi ummat). Dua jenis ajaran (ibadah dan akhlak) adalah ajaran yang bersifat absolut, artinya ajaran ibadah dan akhlak akan selalu relevan disepanjang waktu dan zaman meskipun waktu dan zaman tersebut akan mengalami perubahan. Sedangkan ajaran Islam yang ketiga akan mengalami perubahan sesuai dengan situasi dan kondisi. Namun yang menjadi keunikan dalam ajara Islam adalah, ketiga esensi tersebut dapat dilakukan dalam satu waktu. Seperti contoh seorang yang sedang bekerja akan tetapi niat karena lillahi ta'ala maka orang tersebut sudah menerapkan aspek ibdah kepada Allah.

Sebagai ajaran yang mengatur hubungan sosial, Islam sangat memperhatikan aspek kesejahteraan ummat. Perekonomian ummat sebagai salahsatu faktor kesejahtreaan menjadi perhatian besar dalam Islam. Sehingga Islam menganjurkan manusia untuk terus berusaha memenuhi kebutuhan hidup tanpa mengabaikan esensi ajaran Islam berupa ibadah dan akhlak. Ajaran ini telah Allah firmankan didalam al-Quran surah al-Jumat ayat 9-10

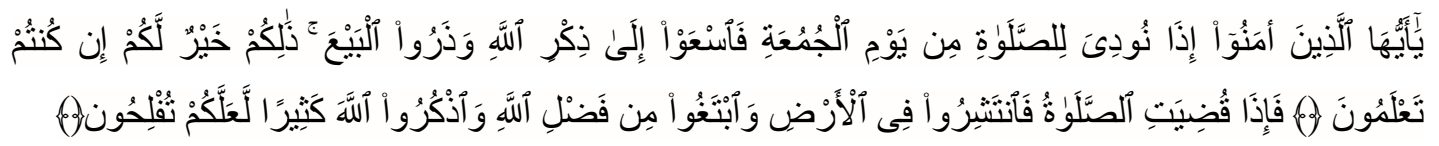
"Hai orang-orang beriman, apabila diserukan kepadamu untuk menunaikan shalat Jum'at, maka bersegeralah kamu kepada mengingat Allah dan tinggalkanlah jual beli. Yang demikian itu lebih baik bagimu jika kamu mengetahui. Apabila shalat telah dilaksanakan, maka bertebaranlah kamu di muka bumi dan carilah karunia Allah dan ingatlah Allah banyak-banyak supaya kamu beruntung”. 
Dua ayat tersebut memberikan pelajaran yang sangat normatif kepada manusia, bagaimana manusia harus berprilaku sebagia hamba allah yang taat dan sekaligus sebagai makhluk sosial yang harus memenuhi kebutuhan hidup. Ayat tersebut memberikan ajaran bagaimana seharusnya yang dilakukan oleh ummat muslim sebagai hamba Allah yang mengemban tugas ibadah sekaligus sebagai makhluk sosial yang harus memenuhi kebutuhan didunia ini. Didalam ayat tersebut Allah menegaskan kepada ummat muslim untuk segera melaksanakan ibadah (berupa shalat jum'at) apabila waktu shalat sudah tiba maka sebagai manusia yang taat harus meninggalkan aktivitas perekonomian (berupa perniagaan/jual beli), namun setelah shalat dilaksanakan Allah memerintahkan hambanya untuk mencari karunianya/rezeki yang termasuk bagian dari aktivitas perekonomian.

Permasalahan perekonomian tidak hanya usrusan individu semata, akan tetapi ajaran Islam sangat mengutmakan ajaran tolong menolong (تعاون). Belasan abad yang lalu Islam telah memberikan gambaran proses talong menolong yang dilakukan oleh Rasullah dikalangan kamu muhajirin (kelompok pendatang dari kota mekkah) dengan kamu anshar (penduduk asli kota madinah) dalam rangka untuk memenuhi kebutuhan hidup kaum muhajirin. Rehabilitasi kehidupan muhajirin dilakukan oleh Rasulullah dengan cara membuat kontrak kerjasama, memperkerjakan kaum muhajirin pada usaha kaum anshar dan lain sebagainya. Apa yang telah dilakukan oleh Rasulullah sebagai kepala negara memberikan gambaran bahwa kebuthan ummat atau kesejahteraan ummat juga menjadi tanggung jawab bagi pemerintah. Oleh karena itu, mensejahterakan kehidupan masyarakat merupakan kewajiban yang harus di penuhi oleh setiap negara.

Di Indonesia UMKM (Usaha Mikro Kecil Menengah) menjadi garda penggerak terhadap aktifitas perekonomian masyarakat. Melalui UMKM permasalahan pengangguran dan kemiskinan dapat terpecahkan, oleh karena itu, UMKM juga disebut sebagai generator pembaharuan kesejahteraan ekonomi masyarakat, karena memiliki peran strategis dalam mengatasi kemiskinan. UMKM adalah pelaku usaha ekonomi dalam kategori pelaku usaha berskala kecil dikelola secara sederhana serta menggunakan tekhnologi sederhana (Laena, 2010). Keberada UMKM menjadi sangat urgen bagi masyarakat karena dapat meberikan solusi bagi tenaga kerja yang belum tertampung. Hal ini dikarenakan UMKM adalah usaha yang berasal dari pemikiran kereatif seseorang dan tidak memiliki kriteria yang tinggi 
dalam menyerap tenaga kerja. Realitanya UMKM telah mampu bertahan dalam mensejahterakan kehidupan masyarkat baik dalam kondisi normal ataupun dalam kondisi krisis ekonomi, faktanya pada krisis ekonomi 1997 UMKM mampu memberikan solusi dan terus betahan sampai kondisi ekonomi kembali stabil.

Perkembangan UMKM di Indonesia semakin meninkat dari beberapa tahun terakhir ini, hingga saat ini tercatat sekitar 65 juta UMKM yang telah tersebar di seluruh belahan nusantara, sejak 2016 jumlah UMKM sekitar 61,7 Juta hingga pada tahun 2018 berkisaran sekitar 64,2 juta (Firdhy Esterina Christy, 2021). Perkembangan UMKM terbesar juga terjadi di wilayah Jawa Timur, bahkan pemprov Jawa Timur akan terus melakukan peningkatan kualitas UMKM, karena pada tahun 2019 sudah berjumlah 9,7 Juta (Zahro, 2019).

Keistimewaan UMKM adalah bisa dilakukan oleh siapa saja, baik masyarakat menengah kebawah atau masyarakat yang taraf ekonomi keatas. Latar belakang pendidikan tidak terlalu di perhatiakan dalam jenis usaha ini, sehingga pendidikan SMP atau SMA pun Melihat banyak yang menekukuni aktifitas UMKM. Pertumbuhan UMKM yang begitu signifikan di Jawa Timur dan didominasi oleh masyarakat yang beragama Islam, maka perlu orientasi terbaru (nem orientation) dalam UMKM, hal ini bertujuan untuk menyeimbangi antara aktifitas ekonomi dengan arah dan tujuan syariat Islam. Oleh karena itu, dalam aktifitas UMKM aspek-aspek maqashidu syariah perlu diperhatikan oleh pelaku.

Penelitian ini bertujuan untuk memberikan arah baru terhadap aktifitas UMKM di Jawa Timur dalam upaya mendukung akselerasi pangsa ekonomi syari'ah. Tujuan yang hendak dicapai adalah terwujudnya UMKM berbasis syari'ah diwilayah Jawa Timur. Penelitian ini juga bertujuan untuk memberikan sumbangsih pemikiran kepada pemerintah Jawa Timur untuk membentuk badan pengawas syariah yang berkerja sebagai pengawas terhadap aktifitas ekonomi syari'ah masyarakat Jawa Timur.

\section{KERANGKA TEORI}

\section{Pengertian Syari'ah}


Secara bahasa شريعة memiliki beberapa makna diantaranya adalah jalan yang nyata dan lurus, tangga atau tempat naik, dan jalan air atau jalan menuju air. Sedangkan secara istilah شريعة adalah:



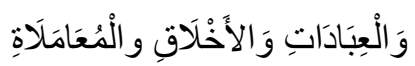

"Suatu aturan Allah terhadap hambanya yang terdiri dari beberapa hukum, kaidahkaidah dan aturan-aturan untuk membangun kehidupan yang adil dan menciptakan kemashlahatan bagi manusia dalam urusan aqidah, ibadah, akhlaq dan mu'amalah".

Didalam al-Qur'an kata syari'ah disebutkan langsung oleh Allah SWT, sebagaimana firman Allah didalam surat al-Maidah ayat 48

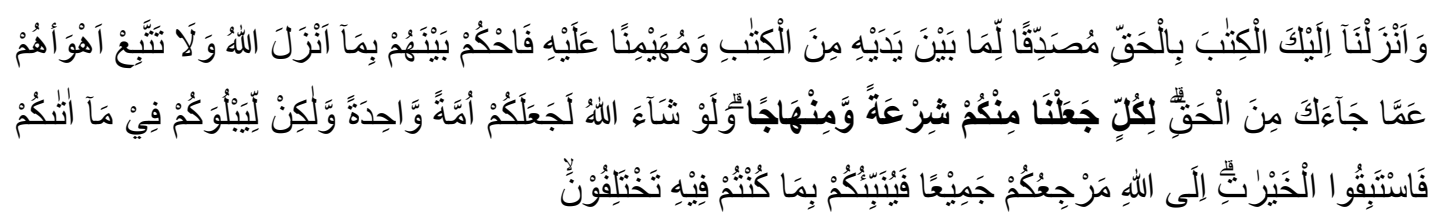

“dan kami telah menurunkan al-kitab (al-Qur'an) kepadamu dengan membawa kebenaran, yang membenarkan terhadap kitab-kitab yang telah diturunkan sebelumnya dan menjaganya, maka putuskanlah perkara mereka menurut apa yang telah diturunkan oleh Allah dan janganlah kamu mengikuti keinginan mereka dengan meninggalkan kebenaran yang datang kepadamu. Untuk setiap ummat diantara kamu, kami berikan aturan dan jalan yang terang, jika Allah menghendaki niscaya kamu dijadikannya satu ummat saja, tetapi Allah hendak menguji kamu terhadap karunia yang telah diberikannya kepadamu, maka berlomba-lombalah dalam membuat kebaikan, hanya kepada Allah kamu kembali, maka diberitahukan kepadamu terhadap apa yang telah kamu perselisihkan”.

Didalam ayat tersebut kata syari'ah memiliki arti aturan, yaitu aturan-aturan terhadap kehidupan manusia baik yang mengatur tentang persoalan ibadah ritual ataupun aturan yang mengatur persoalan-persoalan sosial. Oleh karena itu, syari'at juga dapat dimaknai sebagai aturan-aturan Allah yang berhubungan dengan perbuatan manusia baik dari aspek perbuatan, persoalan keyakinan maupun urusan etika sebagai makluk Allah. 


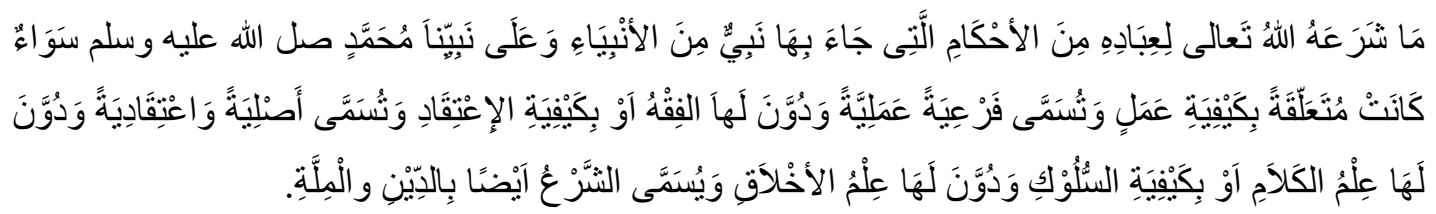
"Syari'at adalah hukum yang ditetapkan oleh Allah kepada hambanya, yang dibawa oleh salah para nabi, termasuk nabi Muhammad SAW. baik hukum yang berhubungan dengan cara beramal yang disebut dengan hukum cabang dan amalan sehingga dikodifikasikanlah ilmu fikih, atau hukum yang berhubungan dengan persoalan keyakinan atau keimanan yang dikenal dengan istilah hukum pokok dan keyakinan sehingga disusunlah ilmu kalam, atau berkenaan dengan tingkahlaku manusia sihingga disusunlah ilmu akhlak, syari'at disebut juga denggan ad-Din dan al-Millah”.

Kata lain dari syari'at adalah ad-Din dan al-Millah, secara harfiyah الدِيّنُ:المِلَّةُ memiliki pengertian yang sama yaitu bermakna agama, namun kedua istilah tersebut digunakan dalam konteks yang berbeda, al-Millah diperuntukkan kepada nabi yang kepadanya agama tersebut diwahyukan sedangkan kata ad-Din digunakan ketika dihubungkan dengan satu agama, sifat agama atau dihubungkan dengan Allah yang telah mewahyukan agama (Nasution, 1992).

Dr. (HC) K.H. Afifuddin Muhajir, M.Ag, pada saat penganugrahan gelar Doctor Honoris Causa menyampaikan bahwa syari'at memiliki dua pengertian yaitu pengertian syari'at secara luas dan secara sempit. Secara umum syari'at Islam sama dengan ad-Din alIslam. Agama Islam (ad-Din al-Islam) memiliki tiga komponen besar yaitu: Akidah, Tasawwuf dan syari'ah. Ajaran akhlaq dan tasawwuf bersifat absolut yaitu selalu relevan di sepanjang zaman meskipun zaman mengalami perubahan serta perkembangan. Sedangkan syari'at (hukum Islam) senantiasa mengalami perubahan sesuai dengan zaman dan masanya.

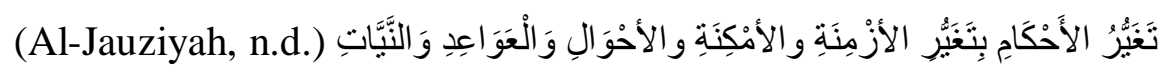
"Hukum bisa berubah sesuai dengan perubahan masa, tempat, keadaan, adat istiadat, serta keinginan manusia”.

الأحكام sedang syari'ah secara sempit merupakan bagian dari pada agama Islam yaitu aturan yang bersifat praktis yang mengatur tingkahlaku manusia baik hubungan 
dengan sesama manusia maupun yang berhubungan dengan Allah, dalam pengertian ini syari'ah ada dua bagian yaitu: syari'at yang bersifat tetap (tsawabit) dan bisa beradaptasi pada taraf peradaban manusia (mutaghoiyirot). Ajaran syari'at yang tsawabit tampak jelas dalam pekara ibadah ( habl min allah), meskipun perkembangan zaman sudah jauh berubah namun pelaksanaan ibadah shalat, puasa, haji zakat tetap tidak mengalami perubahan. Sementara ajaran syari'ah yang mutaghaiyirat nampak jelas dalam perkara mu'amalah (habl min an-nas) yang mengatur aturan main (rules of the game) dalam kehidupan sosial.

Dari pengertian syari'ah diatas, syari'at juga disebut sebagai esensi dari ajaran Islam atau agama Islam yang dapat mengatur elemen-elemen penting seperti persoalan-persoalan ibadah, persoalan moralitas, persoalan hubungan interaksi sosial serta persoalan-persoalan pemenuhan kebutuhan. Oleh karena itu, tampak sangat jelas bahwa syari'at Islam atau agama Islam bukan agama yang hanya mengatur persoalan ibadah dan urusan keimanan semata, akan tetapi syari'at Islam mengatur seluruh aspek kehidupan manusia termasuk kehidupan sosial masyarakat serta urusan perekonomian ummat, politik dan lain sebagainya. Dalam makna lain, syari'at Islam merupakan ajaran yang konprehensip dan universal. Konprehensip berarti memuat aturan atau ajaran dari semua aspek kehidupan baik persoalan habl min Allah maupun habl min an-nas. Sedangkan keuniversalan syari'ah tampak jelas pada penerapan syari'ah yang dapat diterapkan dimana dan kapan saja.

\section{Maqashid Syari'ah}

Maqashid syari'ah secara harfiyah merupakan istilah yang tersusun dari dua kata, maqashid (مقاصد) dan Syari'ah (شريعة). Maqashid memiliki arti tempat tujuan sedangkan syariah memiliki arti menjelaskan dan menerangkan. Pada hakikatnya tidak ada satu syari'at atau aturan yang diciptakan kecuali memiliki tujuan yang hendak dicapai. Dalam kajian Islam tujuan syari'at (maqashid al-Syari'ah) memiliki kajian disiplin ilmu tersendiri. Inti dari maqashid al-Syari'ah adalah kemaslatan seorang hamba baik didunia maupun diakhirat. Esensi dari kemaslahatan tersebut terletak pada mendatangkan kebaikan dan menolak kerusakan (جلب المنفعة ودفع المضرة) didasarkan pada lima prinsip maqashid alSyari'ah yaitu: memelihara agama (حفظ الين) memelihara jiwa (حفظ النفس) memelihara akal memelihara keturunan (حفظ العقل) (حفظ النسل) dan memelihara harta (حفظ المال). 


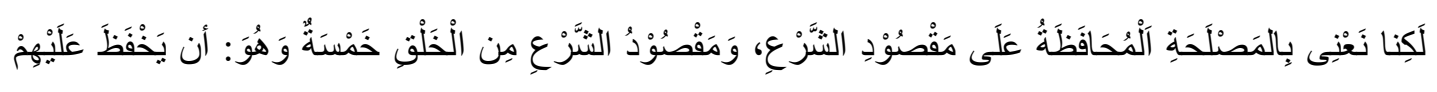

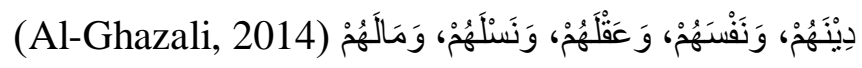
“yang kami maksud dari mashlahah adalah menjaga tujuan syari'at, sedangkan tujuan syari'at kepada makhluk Allah ada lima yaitu: menjaga agama, jiwa, 'akal, keturunan dan menjaga harta".

Berdasarkan skala prioritasnya lima prinsip maqashid al-Syari'ah tersebut dibagi menjadi tiga peringkat kebutuhan yang terdiri dari: kebutuhan dharuriyah, kebutuhan hajiyah dan kebutuhan tahsiniyah. Pertama, Kebutuhan dharuriyah adalah kebutuhan yang paling esensial demi tercapainya stabilitas kehidupan beragama dan berbangsa, yaitu lima prinsip maqashid al-Syari'ah itu sendiri. Kedua, Kebutuhan hajiyah adalah kebutuhan yang membawa manusia kepada keleluasan hidup dan dapat menghindarkan manusia dari kesulitah kehidupan, jika kebutuhan ini tidak terpenuhi tidak sampai mengganggu sampai ketarap kebutuhan dharuriyah. kebutuhan dharuriyah bertujuan untuk kehidupan dunia dan akhirat sedangkan kebutuhan hajiyah diperuntukkan untuk menghilangkan kesulitan dalam pelaksanaan dharuriyah. Ketiga, Kebutuhan tahsiniyah adalah kebutuhan yang menunjang peningkatan taraf kehidupan hamba dihadapan Allah, yang sesuai dengan nilai-nilai moral masyarakat setempat.

Maqashid Syari'ah menurut Syekh wahbah al-Zuhaily adalah subtansi dan tujuan yang diperhatikan dalam pembentukan hukum syari'at, Maqashid Syari'ah merupakan rahasia yang diciptakan oleh Allah dalam setiap hukum yang telah ada (Al-Zuhaili, 1989).

\section{UMKM}

Usaha Mikro Kecil Menengah (UMKM) adalah jenis usaha masyarakat dimana pendiriannya berdasarkan inisiatif sendiri. Adapun pengertian UMKM dalam Undangundang no 20 tahun 2008 adalah sebagai berikut: yang dimaksud dengan usaha mikro adalah usaha produktif milik orang perorangan atau badan usaha perorangan yang telah memiliki kriterian usaha mikro sebagaimana yang telah diatur dalam undang-undang tersebut. Yang dimaksud dengan usaha kecil adalah usaha ekonomi produktif yang dilakukan oleh seseorang atau perorangan yang bukan merupakan cabang atau anak cabang perusahaan yang dimiliki atau yang dikuasai. Sedangkan usaha menengah adalah usaha ekonomi produktif yang berdiri sendiri, yang dilakukan oleh orang perorangan atau badan 
usaha yang bukan merupakan anak perusahaan atau cabang perusahaan yang dimiliki, dikuasai, atau menjadi bagian baik langsung maupun tidak langsung dengan Usaha Kecil atau Usaha Besar dengan jumlah kekayaan bersih atau hasil penjualan tahunan sebagaimana diatur dalam UndangUndang ini (Umum, 2017).

Keriteria UMKM dapat dilihat dari jumlah aset dan omzet serta berdasarkan pengelompokan jumlah tenaga kerja. Hal ini juga telah diatur dalan Undang-undang no 20 Tahun 2008. Usaha mikro adalah jenis usaha yang memiliki aset maksimum 50 juta dan hasil penjualan maksimal 300, usaha kecil memiliki aset diatas 50 juta dan batas maksimum 500 juta dan hasil penjualan maksimal diatas 300 juta sampai 2 milyar 500 juta rupiah. Sedang usaha menengah adalah usaha yang memiliki aset diatas 500 juta dan maksimal 10 milyar dan memiliki hasil penjualan diatas 2 milyar 500 juta sampai 50 milyar. Berikut tabel penjelasan

\begin{tabular}{|l|l|l|l|}
\hline NO & Uraian & Aset & Omset \\
\hline 1 & Usaha Mikro & Max 50 juta & Max 300 juta \\
\hline 2 & Usaha Kecil & $>50$ Juta-500 Juta & $>300$ juta-2,5 Milyar \\
\hline 3 & Usaha Menengah & $>500$ Juta -10 Milyar & $>2,5$ Milyar-50 Milyar. \\
\hline
\end{tabular}

Pada hakikatnya UMKM tidak hanya dapat dibedakan melali aset dan omset semata, namun UMKM memiki ciri dan karekteristik tersendiri. Usaha mikro pada biasanya dalam segi permodalan belum mengenal perbankan akan tetapi lebih mengenal rentenir, tidak memiliki legalitas usaha, SDM sangat lemah. Sedangangkan usaha kecil memiliki ciri: dari segi permodalan sudah berhubungan dengan pihak perbankan, sudah memiliki legalitas usaha, SDM sudah mulai maju dan dilatarbelakangi pendidikan SMA. Sementara usaha menengah memiliki ciri-ciri: dari segi permodalan sudah sering bermitra dengan perbankan, sudah memiliki segala persyaratan legalitas, kualiatas SDM meningkat dengan menggunakan sarjana sebagai manger.

\section{METODE PENELITIAN}

Penelitian ini menggunakan pendekantan libray research (kajian kepustakaan). Penelitian pustaka adalah serangkaian kegiatan yang berhubungan metode pengumpulan data pustaka, membaca mencatat serta mengelola bahan penelitian (Zed, 2008). Adapun sumber data primer dalam penelitian ini adalah kitab turos yang berkaitan dengan 
Maqashid Syari'ah. Peneliti memilih kitab turos Maqashid Syari'ah karena peneliti ingin memetakan konsep UMKM berdasarkan perspektif Maqashid Syari'ah. Sedangkan sumber data sekunder peneliti peroleh dari buku-buku maqashid syari'ah. adapun tahap-tahap pengumpulan data peneliti lakukan dengan cara: Pertama, peneliti membaca sumber data primer dan sekunder, Kedua, peneliti membuat catatan dari data primer dan skunder tersebut, Ketiga, peneliti mengelola catatan dari dua sumber tersebut.

\section{HASIL DAN PEMBAHASAN}

Berusaha untuk memenuhi kebutuhan hidup bagi manusia adalah suatu kewajiban. Islam sebagai agama yang mengandung rahmat bagi seluruh alam tidak hanya mengatur persoalan ibadah semata. Akantetapi Islam mengatur seluruh sendi-sendi kehidupan manusia baik urusan politik terlebih urusan ekonomi. Dalam aturan-aturan syari'at Islam memiliki maksud atau tujuan tersendiri yang dalam kajian Islam disebut dengan Maqashid Syariah. Dalam konsep Maqasid Syariah ada lima aspek yang harus dijaga oleh manusia, yaitu agama (حفظ الين) jiwa (حفظ النفس) akal (حفظ العقل) keturunan (حفظ النسل) harta (حفظ المال). Kelima aspek tersebut harus melekat dalam aktifitas manusia termasuk aktifitas ekonomi.

UMKM termasuk jenis aktifitas ekonomi yang banyak dilakukan oleh masyarakat Jawa Timur, aktifitas ini muncul dari ide kreatif masyarakat sebagai upaya untuk memenuhi kebutuhan ekonomi dalam rangka untuk memperoleh kesejahteraan. Dalam prinsip Islam kesejahteraan yang hendak dicapai adalah kesejahteraan dunia akhirat.

Peran maqashid syariah dalam pengembangan UMKM bisa diwujudkan kedalam maqashidu syariah al-khamsah. Peran agama (hifz ad-din) sebagai posisi pondasi utama UMKM dapat diwujudkan dalam bentuk aspek spritualitas dan keimanan terhadap Allah. Dengan dorongan spritualitas dan keimanan sebagai dasar dari aktifitas UMKM akan menciptakan iklim UMKM yang seimabang antara kebutuhan pribadi dan sosial, seimbang antara kebutuhan dunia dan akhirat. Hifz ad-din dalam UMKM dapat direalisasikan dalam bentuk ketaatan kepada perintah Allah dan menjauhi semua laranggan Allah. Dari aspek permodalan dan omset, pelaku UMKM menjadikan hifz ad-din sebagai garda terdepan dengan mengutamakan nilai-nilai syari'ah, tidak mencari modal dari hasil riba dan dari 
sumber-sumber yang haramlainnya, serta tidak mencari keuntungan dengan cara yang bathil dan lain sebagainya.

Sedangkan peran hifz an-naps, bagi pelaku UMKM perlu menyadari bahwa keberlangsunga hidup masyarakat adalah hal yang penting untuk diutamakan, oleh karena itu, dalam memabangun UMKM harus melihat dan menganalisa apakah UMKM yang akan kita dirikan akan berdampak terhadap keberlangsungan hidup masyarakat atau malah akan menjadi UMKM yang akan memberi mudharat bagi orang lain. Disamping hal itu perlu diperhatikan aspek jalb al-mashalil dan aspek dar al-mafasid terhadap UMKM yang didirikan. Dari sisi perlindungan konsumen, maka aspek hifz an-naps harus berupa perhatian terhadap barang-barang yang diproduksi. Oleh karena itu UMKM yang akan berdiri harus mendapatkan paling tidak dua legalitas yaitu: legalitas dari dinas kesehatan dan legalitas dari majelis ulama'. Legilitas dari dinas kesehatan sebagai tindakan preventif terhadap produksi barang yang menimbulkan dampak berbahaya terhadap keselamata jiwa konsumen. Sedangkan legalitas majelis ulama' merupakan tindakan preventif terhadap produksi barang yang dilarang oleh syari'at Islam.

Hifz al-aql dan hifz an-nasl akan berhubungan dengan pelaku individu UMKM itu sendiri. Prinsip ini akan menjadi kebutuhan individu pelakuk UMKM seperti kebutuhan fisik, psikologi dan kesehatan. Akal merupakan anugrah Alla SWT kepad setiap manusia, dalam UMKM peran akal menjadi tolak ukur dari aktifitas UMKM, akal yang sehat akan menciptakan UMKM yang sehat, akan menciptakan persaingan yang kompetitif.

Sedangkan hifz al-mal merupak hal yang urgen dalam UMKM sebagai upaya untuk mensejahterakan kehidupan masyarakat. Pada akirnya segala aktifitas UMKM akan berhubungan dengan hifz al-mal. Hifz al-mal tidak hanya dilakukan dalam bentuk tabungan semata, namun mendistribusikannya sesuai dengan anjuran dan perintah dalam Islam, seperti membayar zakat, bershadakah, infak dan lain sebagainya. Seorang pelaku UMKM akan membutuhkan kapital untuk memberlangsungkan usahanya, hifz al-mal harus menjadi pondasi terhadap modal tersebut. Hifz al-mal adalah menjaga harta, namun dalam UMKM harta tersebut tidak hanya keuntungan yang diperoleh akan tetapi juga modal yang di gunakan untuk berusaha. 
Untuk mewujudkan dan menerapkan maqashid as-syari'ah pada setiap UMKM maka perlu intervensi pemerintah terhadap regulasi pendiri UMKM. Otoritas pemeritah dalam hal ini adalah melakukan perencanaan, pelaksanaan, evaluasi dan tindak lanjut. Dalam hal perencanaan pemerintah perlu membuat trobosan baru terhadap regulasi UMKM seperti aspek permodalan dan lain sebagainya. Setelah dilakukan perencanaan pemerintah menerapkan apa-apa yang telah berada didalam regulasi yang telah disusun. Peran permerittah tidak hanya berhenti sebatas pelaksanaan akan tetapi tindakan pemantauan dan evaluasi jauh lebih penting.

\section{KESIMPULAN}

Untuk mewujudkan UMKM yang sesuai dengan prinsip-prinsip syari'ah perlu keterlibatan pemerintah untuk membuat regulasi terkait tekhnis dan pelaksanaan dari UMKM. Adapun standar UMKM syari'ah adalah UMKM yang telah melakukan prinsipprinsp syari'ah. ada lima aspek yang harus dijaga oleh manusia, yaitu agama (حفظ الين) jiwa (حفظ العقل) (حفظ (حفظ النسل) heturunan (حفظ) harta (حفظ) (حفل)

\section{DAFTAR PUSTAKA}

Al-Ghazali, A. H. (2014). al-Mustashfa min 'ilm al-Ushul. Dar al-Kotob al- Ilmiyah.

Al-Jauziyah, I. Q. (n.d.). 'Ilam al-Muwaqi' in 'an Rabbi al-Alamin. dar al-jayl.

Al-Zuhaili, M. W. (1989). al-Fiqh al-Islami wa Adillatuhu. Dar al-Fikr.

Firdhy Esterina Christy. (2021). Jumlah UMKM di Indonesia. Tempo.co. https://data.tempo.co/read/1111/jumlah-umkm-di-indonesia

Laena. (2010). Membedah UMKM Indonesia: Sebuah Kajian Tentang Strategi Pemberdayaan \& Pengembangan Usaha Mikro Kecil Menengah di Indonesia. Lugas Poundation.

Nasution, H. (1992). Ensiklopedi Indonesia. Sobdodadi.

Umum. (2017). Undang-Undang Nomor 20 Tahun 2008 Tentang Usaha Mikro, Kecil, dan Menengah.https://www.ojk.go.id/sustainable-finance/id/peraturan/undangundang/Pages/Undang-Undang-Republik-Indonesia-Nomor-20-Tahun-2008Tentang-Usaha-Mikro,-Kecil,-dan-Menengah.aspx

Zahro, F. (2019). Dinkop Jatim Dorong UMKM Naik Kelas di Tahun 2020, Lewat Program MJC ESJC dan OPOP Artikel ini telah tayang di Surya.co.id dengan judul Dinkop 
Jatim Dorong UMKM Naik Kelas di Tahun 2020,Lewat Program MJC ESJC dan OPOP Artikel ini telah tayang di Surya.co. Surya.co.id. https://surabaya.tribunnews.com/2019/12/17/dinkop-jatim-dorong-umkm-naikkelas-di-tahun-2020-lewat-program-mjc-esjc-dan-opop

Zed, M. (2008). Metode Penelitian Kepustakaan. Yayasan Obor Indonesia. 